УДК/UDC 343.9

\title{
Молодежный экстремизм: проблемы и пути решения
}

\author{
Батюкова Вера Евгеньевна \\ старший научный сотрудник сектора уголовного права, уголовного процесса и \\ криминологии, кандидат юридических наук, доцент \\ Институт государства и права Российской академии наук (ИГП РАН) \\ г. Москва, Россия \\ e-mail: Batuykova@yandex.ru
}

\section{Аннотация}

Актуальность изучения этой темы в доктрине уголовного права подтверждается наличием целого пласта неурегулированных правоотношений в исследуемой области, трудностей, возникающих в правоприменительной и судебной практике, различных толкований признаков указанных преступлений. Все эти обстоятельства порождают не только научный интерес, но и споры, существующие на протяжении всего времени действия уголовного закона. Основным вопросом обсуждения остается проблема противодействия экстремизму, зарождающемуся в молодежной среде. В статье автором рассматривается современное состояние экстремизма в молодежной среде, анализируются причины развития экстремизма среди молодежи, ключевые проблемы и пути их решения. Приводится статистика совершения преступлений экстремистской направленности, даются примеры из судебной практики. Анализируются данные, полученные в ходе социологического опроса.

Ключевые слова: экстремизм, молодежная среда, уголовная ответственность, приговор суда, судебная статистика, противодействие, причины.

\section{Youth extremism: problems and solutions}

\section{Batyukova Vera Yevgenyevna}

Senior Researcher of the Sector of Criminal Law, Criminal Procedure and Criminology, Candidate of Law, assistant professor

Institute of State and Law of the Russian Academy of Sciences

Moscow, Russia

e-mail: Batuykova@yandex.ru 


\begin{abstract}
The relevance of studying this topic in the doctrine of criminal law is confirmed by the presence of a whole layer of unsettled legal relations in the studied area, difficulties arising in law enforcement and judicial practice, various interpretations of the signs of these crimes. All these circumstances give rise not only to scientific interest, but also to disputes that have existed throughout the entire duration of the criminal law. The main issue of discussion remains the problem of countering extremism emerging in the youth environment. In the article, the author examines the current state of extremism in the youth environment, analyzes the reasons for the development of extremism among young people, key problems and ways to solve them. The statistics of committing extremist crimes is given, examples from judicial practice are given. The data obtained in the course of a sociological survey are analyzed.
\end{abstract}

Key words: extremism, youth environment, criminal responsibility, court verdict, judicial statistics, opposition, reasons.

Молодежь выступает в роли важного ресурса в России и в обществе. Глобальный характер изменений, происходящих в экономической, политической и идеологической сферах, привел к утрате жизненных ориентиров у части российской молодежи. В обществе разрушена старая система ценностей, а новая еще не сформирована. В условиях социальных волнений и материального неблагополучия стали появляться радикальные группы агрессивной ориентации, пропагандирующие идеи национальной, расовой и религиозной нетерпимости. Большинство из них - молодежь в возрасте от 14 до 30 лет. Так, совсем недавно возник такой социальный феномен, как молодежный экстремизм, который стал предметом исследования ученых в различных областях права, социологии и педагогики. Статистика количества преступлений, зафиксированных в этой категории, показывает то, что проблема противодействия экстремизму не потеряла сегодня своей актуальности [1].

Экстремизм в России уходит своими корнями в эпоху XIX в., в период бурных общественно-политических изменений в социуме. Экстремизм проявляется в переломные для общества моменты, когда общество отходит от прежних политических, моральных, культурных ценностей, 
но не успевает принять новые, в связи с чем возникает некий вакуум, который стремятся заполнить различные общественно-политические группы или объединения экстремисткой направленности. Это явно прослеживалось в период 90-х гг. ХХ в., когда вследствие разрухи, кризиса и упомянутых выше обстоятельств появились и получили развитие многочисленные экстремистские группы политической, национальной, религиозной направленности (Свидетели Иеговы, татарские и чеченские сепаратисты, исламские террористы и т. п.). Молодежный экстремизм же занимает особое место ввиду ряда характерных особенностей и черт.

Однако при рассмотрении данной темы представляется необходимым дать соответствующие определения терминам «экстремизм» и «молодежный экстремизм». Под экстремизмом можно понимать противоправную деятельность, осуществляемую сторонниками определенных политических, религиозных и иных идей, ценностей и убеждений, направленную на разрушение конституционного строя государства посредством насильственных действий. Также экстремизм можно трактовать как теорию и практику достижения социально-политических, религиозных, национальных целей посредством «крайних», запрещенных способов, среди которых выделяют запрещенные законом применение силы, насилие, посягательство на права и свободы человека и гражданина.

Однако наиболее полно понятие экстремизма и экстремисткой деятельности посредством ее видов раскрывается в п. 1 ст. 1 Федерального закона от 25 июля 2002 г. № 114-ФЗ «О противодействии экстремистской деятельности». Согласно положениям данного закона под экстремизмом понимается:

1) насильственное изменение основ конституционного строя и (или) нарушение территориальной целостности Российской Федерации (в т. ч. отчуждение части территории Российской Федерации), за исключением делимитации, демаркации, редемаркации Государственной границы Российской Федерации с сопредельными государствами; 
2) публичное оправдание терроризма и иная террористическая деятельность;

3) возбуждение социальной, расовой, национальной или религиозной розни;

4) нарушение прав, свобод и законных интересов человека и гражданина в зависимости от его социальной, расовой, национальной, религиозной, языковой принадлежности или отношения к религии, а также иные формы экстремизма, далее перечисляемые в данном Федеральном законе [2].

Исходя из всего вышеперечисленного, следует заключить, что молодежным экстремизмом является совершение указанных противоправных действий людьми или группами лиц, подпадающими под определение молодежи, т. е. лицами в возрасте от 14 до 30 лет.

На сегодняшний день экстремизм среди молодежи проявляется в нарушении общепринятых норм в обществе, закона и в появлении неформальных, противозаконных молодежных объединений. Экстремисты не признают людей, принадлежащих к другим социальным группам, статусам, которые также принадлежат к другой национальности и придерживаются иных политических, правовых, экономических, моральных, эстетических и религиозных идей. Совершенствование молодежного экстремизма показывает слабую социальную приспособленность молодежи, формирование в сознании асоциальных установок, порождающих противоправное поведение.

Исследования показывают, что растет экстремизм во всех его формах, и это напрямую связано с ростом преступности в обществе. Члены экстремистских молодежных организаций, прикрываясь идеологическими лозунгами, часто занимаются преступной деятельностью (убийства, кражи, кражи, хулиганство, вандализм и т. д.).

Растущее влияние религиозного и этнонационального фактора является основной тенденцией в развитии молодежного экстремизма.

Информационно-коммуникационная сеть «Интернет» (далее по тексту - интернет) играет определенную роль в процессе роста деструк- 
тивного поведения среди молодежи, а также является одним из основных способов вербовки новых экстремистов, т. к. посредством общения в интернете происходит коммуникация экстремистов с потенциальными (новыми) членами экстремистских группировок. Также имеет место быть феномен «самовербовки», т. е. идеология пользователей интернета радикализируется под влиянием пропаганды.

Особым фактором, влияющим на степень распространения экстремизма среди молодежи, являются также неконтролируемые миграционные процессы. Отсутствие строго контроля в сфере миграции создает благоприятную почву для распространения и расширения экстремистских группировок и сообществ. Эти моменты важно учитывать при осуществлении государственной миграционной политики в России. На наш взгляд, следует пересмотреть либеральные подходы в сфере регулирования миграции населения.

K основным характерным чертам современного молодежного экстремизма в России можно отнести следующие:

1) повышающаяся сплоченность и организованность групп;

2) появление конкретной идеологии;

3) повышение конспирации;

4) применение интернета в целях коммуникации и координации действий, а также проведения идеологической пропаганды;

5) улучшение связи между международными и внутригосударственными радикальными группами.

Экстремизм ввиду его опасности для конституционного и общественного строя в настоящее время является одной из актуальных угроз российского и мирового общества. Экстремизм способен расшатать государственные системы и институты, привести к этническим, религиозным и иным конфликтам, к распаду страны и иным разрушительным последствиям. Молодежи в силу ее физических и психологических особенностей присущи радикализм во взглядах и оценках, максимализм в суждениях, в неприятии несправедливости, подверженность влиянию со стороны идеологов радикальных учений, особенно когда подобная идео- 
логия строится на патриотических настроениях и религиозных чувствах, имеет подстрекательский, агрессивный и насильственный характер. Соответственно, основным отличием молодежного экстремизма от экстремизма вообще являются возрастные рамки его последователей и связанные с этим формы проявления и поведения.

Правовую основу борьбы с молодежным экстремизмом составляют:

1) Конституция Российской Федерации (ст. 13 - организация и существование общественных объединений экстремистской направленности);

2) У Уоловный кодекс Российской Федерации (ст. 20 5.2, 280, 280.1, 282, 282.1, 282.2 - публичные призывы к террористической деятельности или публичное оправдание терроризма, организация экстремистского сообщества, организация деятельности экстремистской организации и т. д.);

3) Кодекс Российской Федерации об административных правонарушениях (ст. 5.26 - нарушение норм права о свободах совести, вероисповедания и о религиозных объединениях; ст. 20 .3- пропаганда и демонстрирование нацистской атрибутики или символики, ст. 20 .29 - производство, а также распространение экстремистских материалов);

4) Федеральный закон «О противодействии экстремисткой деятельности», Федеральный закон «О противодействии терроризму» (акты, составляющие правовой базис борьбы с экстремисткой деятельностью);

5) Концепция противодействия экстремизму в Российской Федерации [3] и иные нормативно-правовые акты.

Министерство внутренних дел Российской Федерации, а также органы государственной власти и местного самоуправления в настоящее время активно сосредоточены на борьбе с экстремизмом среди молодежи. Это является одной из приоритетных задач государства.

Указом Президента Российской Федерации от 26 декабря 2011 г. образована Межведомственная комиссия по противодействию экстремизму 
в Российской Федерации [3; 4] в целях координации деятельности органов государственной власти и местного самоуправления. Комиссия отвечает за организацию взаимодействия государственных органов в сфере противодействия экстремизму, а также осуществляет надзор за реализацией государственной политики в этой сфере.

Министерством внутренних дел Российской Федерации принимается большая часть всех мер в сфере реализации необходимых направлений государственной политики в вопросе противодействия молодежному экстремизму.

Правоохранительные органы не только занимаются пресечением экстремистских деяний, но и ведут их расследование, а также устраняют последствия совершенных преступлений. Следует отметить, что органы правоохранительной власти не в силах бороться с экстремизмом самостоятельно, эффективность борьбы зависит от налаженности системы предупреждения в целом и от грамотно проведенной профилактики. Конечно, на правоохранительные органы возлагается большая ответственность в борьбе с молодежным экстремизмом, но это довольно сложный процесс, предполагающий наличие вспомогательных факторов. Государство закрепляет основы и ориентиры профилактики экстремизма, но органы местного самоуправления более компетентны в данном вопросе, т. к. у них осуществляется постоянный контакт с населением, а также есть понимание об актуальных проблемах общества в целом и молодежи в частности.

Полномочия органов местного самоуправления в борьбе с экстремизмом и по его профилактике закреплены в Федеральном законе «О противодействи и экстремистской деятельности» и в Федеральном законе от 6 октября 2003 г. № 131-Ф3 «Об общих принципах организации местного самоуправления в Российской Федерации» [5].

$\mathrm{K}$ сожалению, далеко не каждый регион использует возможности органов местного самоуправления по борьбе с экстремизмом. Считаем, что причиной данной проблемы является некое обособление местных органов от проблемы противодействия молодежному экстремизму, а также 
использование органами местного самоуправления недостаточно эффективных форм профилактики данного явления, что имеет негативный эффект [6].

Отраженные на законодательном уровне полномочия органов местного самоуправления не позволяют последним осуществлять стабильную, постоянную профилактическую работу среди молодежи. В связи с этим видна тенденция минимизации вовлеченности органов власти в процесс предупреждения молодежного экстремизма. Хотя именно работа органов местного самоуправления является основополагающей и необходимой в данном процессе. Скорее всего, проблема кроется в недостаточном финансировании борьбы с молодежным экстремизмом на уровне субъектов.

Причины и предпосылки молодежного экстремизма достаточно разнообразны по своей природе. Так, можно выделить:

1) психологические и социально-психологические: значительный радикализм во взглядах и суждениях, максимализм, желание достичь результата здесь и сейчас, обостренное чувство справедливости, ухудшение психологического климата в семье и ослабление ее воспитательных возможностей [7];

2) социально-экономические: безработица, инфляция, нищета;

3) социально-политические: наличие нерешенных этнических и/или религиозных конфликтов, этническая и религиозная напряженность.

Также среди причин можно назвать недостатки образовательной и правоохранительной системы (недостаточная эффективность системы воспитательного воздействия на лиц, неприспособленных к общественной среде, отсутствие действенной социальной профилактики проявлений экстремизма и т. п.) [8].

Судебная статистика является ценным источником информации о составе и структуре молодежного экстремизма. Так, согласно ей $97 \%$ осужденных за совершение экстремистских преступлений экстремистской направленности являются мужчинами. Доля преступлений, кото- 
рые были совершены единолично, составила 14,9 \% от общего числа экстремистских преступлений, а доля преступных деяний в составе группы лиц - 85,1\%. 91,2\% групповых преступлений были совершены в составе группы лиц одной национальности. Доля лиц младше 30 лет составляет $85,4 \%$ от абсолютного числа участников указанных преступных групп. По показателю численности преобладают малочисленные (от 2 до 5 человек - 55,8 \%) и средние (от 5 до 10 человек - 39,2 \%) преступные группы. Осуществляя анализ деятельности экстремистских движений, активных на территории Российской Федерации, необходимо упомянуть, что преступления в $42 \%$ случаев совершаются участниками неформальных молодежных организаций экстремистской направленности в возрасте от 14 до 30 лет. Также изучение судебной практики показывает, что большая часть лиц ранее не привлекались к уголовной ответственности.

Большую тревогу вызывает тенденция проникновения экстремистских идей и установок в систему воспитания и образования. На сегодняшний день в России весьма слабо поставлена информационно- разъяснительная работа с молодежью по борьбе с экстремизмом. Неудивительно, что именно студенты высших учебных заведений составляют львиную долю рекрутов разнообразных экстремистских организаций.

С другой стороны, ведется активная работа по закреплению на законодательном уровне правил поведения в интернет-пространстве, которое является еще одной площадкой для процветания экстремизма среди молодежи (например, Государственная Дума приняла в третьем чтении президентский пакет законов, где говорилось о частичной декриминализации ст. 282 Уголовного кодекса Российской Федерации) [9].

Однако российскому молодежному экстремизму на сегодняшний день присущ ряд особенностей. Таковыми являются:

1) активное участие молодежи в возрасте от 14 до 30 лет в организованных массовых экстремистских акциях и их интеграция в экстремистские националистически ориентированные неформальные молодежные организации (группы) и экстремистские сообщества; 
2) расширение географии экстремистской угрозы в Российской Федерации;

3) убийства граждан других национальностей или религий и иностранных граждан, совершаемые в Российской Федерации, все чаще становятся серийными, более жестокими, изощренными, профессиональными, издевательскими и ритуальными, а совершение экстремистских действий само по себе становится не только единичным актом, но и профессиональной деятельностью определенных групп людей;

4) стремление экстремистских националистических движений привлечь в свои ряды членов различных агрессивных молодежных субкультур, неформальных молодежных объединений, групп, движений, а также лиц с судимостью;

5) наличие у неформальных молодежных организаций (группировок) экстремистско-националистической направленности признака вооруженности, в т. ч. наличие взрывчатых веществ.

На фоне этих процессов, происходящих в российском обществе, формируется «индивидуальность» как противоположность «коллективности».

Для подтверждения этого тезиса нами было опрошено 120 студентов московских вузов. На вопрос: «Что для Вас является главенствующим?» 34 студента ответили - индивидуальное, 4 студента - общественное и 82 студента - сочетание индивидуального и общественного (в соотношении 70/30), т. е. индивидуальным потребностям отводится большая часть. На вопрос: «Какие интересы для Вас являются преобладающими?» 90 студентов из опрошенных ответили - индивидуальные, 6 студентов - государственные и 24 студента - общественные.

На наш взгляд, именно сбалансированность индивидуального и общественного (коллективного) является условием гармоничного и стабильного развития общества. Преодолевая ошибки и имея некоторый исторический опыт, в настоящее время необходимо найти такой подход и такую сбалансированность интересов личности и общества, которые 
приведут к консолидации, что, в свою очередь, будет в дальнейшем гарантировать национальную безопасность. В противном случае процесс отчуждения власти от общества, углубление социальных противоречий приведут к расколу государственной целостности. Преобладающий сегодня либерализм ведет к обособлению личности, ее безграничной и безудержной свободе и, как следствие, борьбе всех против всех. Особую опасность в этой связи представляет такая социальная группа, как молодежь, поскольку существующие противоречия в обществе накладывают свой отпечаток на формирование личности, комплексного восприятия мира, определение своего места в обществе, баланс «личного» и «общественного».

Рассуждая о молодежном экстремизме, следует привести примеры из практики судебных органов. Так, Кунцевский районный суд Москвы в 2019 г. приговорил 21-летнего студента Ж. к трем годам лишения свободы условно по делу о призывах к экстремизму на youtube-канале. Как сказано в приговоре, Ж. призывал к экстремизму и насильственному свержению конституционного строя, «используя знания, полученные в вузе». Ж. арестовали по делу о несогласованном митинге 27 июля 2019 г. и обвинили в участии в массовых беспорядках. Спустя месяц его перевели под домашний арест из СИЗО, дело о беспорядках прекратили из-за его непричастности, но предъявили новое обвинение в публичных призывах к экстремизму. Позже мера пресечения в виде домашнего ареста была отменена. Ж. ограничили в использовании средств связи и интернета сроком на два года. Суд счел доказательства вины Ж. достоверными, несмотря на непризнание им вины. Эксперт стороны обвинения, на основании заключения которого осудили студента, заявил, что в четырех роликах «прослеживается мотив ненависти к действующей власти» [10].

Но не стоит забывать, что у проблемы молодежного экстремизма существуют определенные решения. Так, среди возможных мер можно предложить:

1) совершенствование законодательства в сфере противодействия молодежному экстремизму; 
2) развитие идей патриотизма, толерантности, веротерпимости в школах и высших учебных заведениях;

3) проведение анонимных опросов в школах и высших учебных заведениях с целью выявления уровня толерантности учащихся к другим национальностям и религиозным верованиям;

4) выявление и перекрытие каналов финансирования экстремистских организаций;

5) повышение уровня жизни населения и помощь незащищенным категориям лиц среди молодежи (нуждающимся, воспитанникам детских домов и т. д.).

В заключение следует отметить, что, несмотря на существование проблемы молодежного экстремизма в России, она не является нерешаемой. Воздействуя различными методами и способами на молодежную среду, можно добиться впечатляющих успехов. Ведь только путем взаимодействия различных общественных, государственных структур и органов власти, проведения информационной и аналитической работы можно решить проблему молодежного экстремизма в России.

\section{Список литературы}

1. Савенков А. Н. Государство и право в период кризиса современной цивилизации. М.: Проспект, 2020. 448 с.

2. О противодействии экстремистской деятельности: Федеральный закон от 25.07.2002 № 114-Ф3 // Собрание законодательства РФ. 2002. № 30. Ст. 3031.

3. О Межведомственной комиссии по противодействию экстремизму в Российской Федерации (вместе с «Положением о Межведомственной комиссии по противодействию экстремизму в Российской Федерации»): Указ Президента РФ от 26.07.2011 № 988 // Собрание законодательства РФ. 2011. № 31. Ст. 4705.

4. О некоторых вопросах Межведомственной комиссии по противодействию экстремизму в Российской Федерации: Указ Президента РФ от 17.02.2016 № 64 // Собрание законодательства РФ. 2016. № 8. Ст. 1098.

5. Об общих принципах организации местного самоуправления в Российской Федерации: Федеральный закон от 06.10.2003 № 131-Ф3 // Собрание законодательства РФ. 2003. № 40. Ст. 3822. 
6. Дондоков Г. Р., Дондоков Ц. С. О некоторых проблемах, стоящих перед органами местного самоуправления в сфере профилактики терроризма и экстремизма среди молодежи // Государственная власть и местное самоуправление. 2020. № 8. C. $47-50$.

7. Фридинский С. Н. Молодежный экстремизм как особо опасная форма проявления экстремистской деятельности // Юридический мир. 2008. № 6. С. 23-25.

8. Мельников В. Ю. Противодействие преступлениям экстремистской направленности в Российской Федерации // Российский следователь. 2020. № 7. С. 57-61.

9. Ортанова Л. Р., Шаваева Д. В, Сижажев А. Т. Экстремизм среди молодежи. Криминологическая характеристика личности преступника-экстремиста // В сборнике: Перспектива-2019. материалы Международной научной конференции студентов, аспирантов и молодых ученых. 2019. С. 365-368.

10. Суд приговорил студента Егора Жукова к условному срок // Новостной портал «РБК» // https://www.rbc.ru/society/06/12/2019/5de94e469a79472ea8b9f836 (дата обращения: 01.07.2021).

\section{References}

1. Savenkov A. N. State and law during the crisis of modern civilization. Moscow: Prospect, 2020. 448 p.

2. On countering extremist activity: Federal Law of 25.07.2002 No. 114-FZ // Collected Legislation of the Russian Federation. 2002. No. 30. Art. 3031.

3. On the Interdepartmental Commission on Counteracting Extremism in the Russian Federation (together with the "Regulations on the Interdepartmental Commission on Countering Extremism in the Russian Federation"): Decree of the President of the Russian Federation of July 26, 2011 No. 988 // Collected Legislation of the Russian Federation. 2011. No. 31. Art. 4705.

4. On some issues of the Interdepartmental Commission on Counteracting Extremism in the Russian Federation: Decree of the President of the Russian Federation of February 17, 2016 No. 64 // Collected Legislation of the Russian Federation. 2016. No. 8. Art. 1098.

5. On the general principles of the organization of local self-government in the Russian Federation: Federal Law of 06.10.2003 No. 131-FZ / / Collected Legislation of the Russian Federation. 2003. No. 40. Art. 3822.

6. Dondokov G. R., Dondokov Ts. S. On some problems facing local governments in the prevention of terrorism and extremism among young people // State Power and Local Self-Government. 2020. No. 8. Pp. 47-50.

7. Fridinsky S. N. Youth extremism as a particularly dangerous form of manifestation of extremist activity // Legal world. 2008. No. 6. Pp. 23-25. 
8. Melnikov V. Yu. Countering extremist crimes in the Russian Federation // Russian investigator. 2020. No. 7. Pp. 57-61.

9. Ortanova L. R., Shavaeva D. V, Sizhazhev A. T. Extremism among youth. Criminological characteristics of the personality of an extremist criminal $/ /$ In the collection: Perspective-2019. materials of the International Scientific Conference of Students, Postgraduates and Young Scientists. 2019. Pp. 365-368.

10. The court sentenced student Yegor Zhukov to a suspended sentence // News portal "RBC" // https://www.rbc.ru/society/06/12/2019/5de94e469a79472ea8b9f836 (date of access: 01.07.2021). 